CARDIOVASCULAR MEDICINE

\title{
Relation between baseline risk and treatment decisions in non-ST elevation acute coronary syndromes: an examination of international practice patterns
}

\author{
P Kaul, L K Newby, Y Fu, D B Mark, S G Goodman, G S Wagner, R A Harrington, C B Granger, \\ F Van de Werf, E M Ohman, P W Armstrong, for the VIGOUR Group
}

Heart 2005;91:876-881. doi: 10.1136/hrt.2004.042887

See end of article for authors' affiliations

Correspondence to: Dr Padma Kaul, University of Alberta, 7221 Aberhart Centre - I, Edmonton, Alberta, Canada T6G 2B7; pkaul@ualberta.ca

Accepted 25 October 2004

\begin{abstract}
Objectives: To examine the interaction between ST segment depression on the baseline ECG and subsequent in-hospital revascularisation on six month mortality among patients with non-ST elevation acute coronary syndromes. To examine whether ST segment depression influenced clinical decision making and whether there was international variation in the use of cardiac procedures across ST segment depression categories.

Methods: 11453 patients enrolled in GUSTO-IIB (global use of strategies to open occluded coronary arteries), PARAGON (platelet llb/Illa antagonism for the reduction of acute coronary syndrome events in a global organisation network) -A, and PARAGON-B were studied. Patients were categorised as having no ST segment depression, $1 \mathrm{~mm}$ ST segment depression in two contiguous leads, and ST segment depression $\geqslant 2 \mathrm{~mm}$ in two contiguous leads. International practice across four geographic regions was examined: USA, Canada, Europe, and Australia/New Zealand.

Results: Revascularisation appeared to have no impact on survival among patients with no ST segment depression; however, revascularisation was associated with a significant survival benefit among patients with ST segment depression $\geqslant 1 \mathrm{~mm}$. There was an inverse relation between the extent of ST segment depression and the use of angiography as well as angioplasty $(p<0.01)$. However, patients with ST segment depression $\geqslant 2 \mathrm{~mm}$ were more likely to undergo bypass surgery. The only significant trend of increasing use of revascularisation procedures with increasing ST segment depression was observed in the USA.

Conclusions: International practice patterns in procedure use appear to be insensitive to the extent of ST segment depression. Major opportunities for more efficient delivery of care exist in all regions.
\end{abstract}

n the ongoing debate regarding conservative versus aggressive treatment of patients presenting with non-ST elevation acute coronary syndromes (ACS), there is growing consensus that high risk patients are likely to benefit most from early revascularisation. ${ }^{1}$ We, and other investigators, have previously shown that identification of high risk patients can be facilitated through the use of a readily available diagnostic tool: the baseline ECG. ${ }^{2-6}$ While there is little doubt that greater ST segment depression on the baseline ECG is associated with worse outcomes among patients with ACS, data from the FRISC-II (Fragmin and fast revascularization during instability in coronary artery disease) and TACTICS-TIMI-18 (treat angina with Aggrastat and determine cost of therapy with invasive or conservative strategy-thrombolysis in myocardial infarction) and a reanalysis of the TIMI-IIIB study suggest that ST segment depression may offer additional insights into identifying optimal candidates for revascularisation. ${ }^{7-9}$

In data from three major international non-ST elevation ACS trials, which were conducted before publication of evidence that revascularisation may be most beneficial among patients with ST segment depression $\geqslant 1 \mathrm{~mm}$, we examined the interaction between the extent of ST segment depression on the baseline ECG and in-hospital revascularisation (percutaneous coronary intervention (PCI) or coronary artery bypass graft surgery (CABG)) on six month mortality outcomes. We also examined the degree of international variation in the use of diagnostic and treatment procedures for these patients during the index hospitalisa- tion. The results of our study would serve as important benchmarks against which the impact of subsequent studies and guidelines on clinical practice can be evaluated.

\section{METHODS}

\section{Study population}

The GUSTO-IIB (global use of strategies to open occluded coronary arteries) ${ }^{10}$ and the PARAGON (platelet IIb/IIIa antagonism for the reduction of acute coronary syndrome events in a global organisation network) -A and PARAGON-B studies $^{11}{ }^{12}$ collectively enrolled 15518 patients with unstable angina and non-ST myocardial infarction over a five year period (1994 to 1998). Inclusion criteria for the three trials were similar: patients presenting with chest discomfort within 12 hours of symptom onset with transient or persistent ST segment depression $\geqslant 0.5 \mathrm{~mm}$ or $\mathrm{T}$ wave inversion, or transient ST segment elevation $\geqslant 0.5 \mathrm{~mm} \mathrm{(30}$ minutes), were eligible for enrolment.

The current study population consisted of 8011 patients enrolled between 1994 and 1995 in GUSTO-IIB, 2282 patients enrolled between 1995 and 1996 in PARAGON-A, and 1160

\footnotetext{
Abbreviations: ACS, acute coronary syndromes; FRISC-II, Fragmin and fast revascularization during instability in coronary artery disease; GUSTO-IIB, global use of strategies to open occluded coronary arteries; PARAGON, platelet llb/llla antagonism for the reduction of acute coronary syndrome events in a global organisation network; PCl, percutaneous coronary intervention; TACTICS-TIMI-18, treat angina with Aggrastat and determine cost of therapy with invasive or conservative strategy-thrombolysis in myocardial infarction
} 
patients enrolled during 1998 in the PARAGON-B troponin substudy. ${ }^{13}$ The 1160 patients enrolled in the PARAGON-B troponin substudy, whose ECGs were evaluated by a central core laboratory, constituted a prospectively selected random sample of the overall 5225 patients enrolled in the PARAGON-B trial. Of the total 11453 patients, baseline ECG data were available for 10369 (91\%). Patients $(\mathrm{n}=1521)$ with factors potentially confounding ECG interpretation - that is, left bundle branch block, right bundle branch block, interventricular conduction delay, left ventricular hypertrophy, ventricular rhythm, or ventricular pacing-were excluded from this study.

\section{ECG parameters}

ECGs were evaluated at central core laboratories at Duke University, the Canadian Heart Research Centre, and the University of Alberta. Baseline ECGs were recorded in 12 lead format at a paper speed of $25 \mathrm{~mm} / \mathrm{s}$. ST segment depression was judged to be present if the $\mathrm{J}$ point was depressed by $1 \mathrm{~mm}$ or more and was followed by a horizontal or downward sloping ST segment for at least 0.08 seconds in all leads except aVR. ST segment depression was measured and rounded off to the nearest $1 \mathrm{~mm}$. For our analysis, patients were categorised into three mutually exclusive groups: no ST depression, $1 \mathrm{~mm}$ ST depression, or $\geqslant 2 \mathrm{~mm}$ ST depression. For limb leads, a minimum of two leads in orderly arrangement (aVL and I, II and aVF, or aVF and III) each having 1 or $2 \mathrm{~mm}$ ST depression was required for qualifying as 1 or $2 \mathrm{~mm}$ ST depression, respectively. For precordial leads, a minimum of two contiguous leads (V1 and V2, V2 and V3, $\mathrm{V} 3$ and $4 \mathrm{~V}$, and so on) each having 1 or $2 \mathrm{~mm}$ ST depression was required for qualifying as 1 or $2 \mathrm{~mm}$ ST depression, respectively.

\section{International practice patterns}

To examine variations in international practice patterns, patients were grouped according to country of enrolment. Four regions were identified: USA (2143); Canada (1023); Europe (4438); and Australia/New Zealand (1013). Owing to the diverse geographic distribution of the remaining 231 patients (Argentina (159), Israel (76), South Africa (46), and Brazil (4)), they were excluded from the analysis. The appendix provides the specific countries constituting each region.

In GUSTO-IIB coronary angiography, PCI and CABG were discouraged for the duration of the study drug infusion (mean duration of treatment was 75 hours) unless there was evidence of recurrent ischaemia. Similarly, in PARAGON-A cardiac procedures were discouraged for the first 48 hours unless clinically necessitated by haemodynamic instability or recurrent ischaemia. In PARAGON-B, the protocol did not specify guidelines regarding the use of cardiac procedures and all procedures were performed according to local standards of practice.

Revascularisation procedures were recorded for all patients if they were done within the index hospitalisation. Thirty day rates of revascularisation reported by patients were also collected in all three trials. Index hospital rates of use of diagnostic procedures (stress tests and angiography) and revascularisation procedures (PCI and CABG) across ST segment depression category, overall and within each region, were compared. The rates of revascularisation procedure use for patients who underwent angiography were also examined.

\section{Statistical analyses}

$\chi^{2}$ tests (for categorical variables) and the non-parametric Kruskal-Wallis tests (for continuous variables) were used to compare characteristics across groups of patients. Angiography and revascularisation procedure rates across ST segment depression categories were compared by $\chi^{2}$ tests for trends. Kaplan-Meier analysis was used to study the association between revascularisation and six month mortality across ST segment depression categories. To reduce selection bias associated with treating patients who did not survive long enough to undergo revascularisation as nonrevascularised patients, we performed a landmark analysis. ${ }^{14}$ In this analysis, which effectively removes the bias as a result of early hazard, only those patients who had survived to six days (that is, who had the opportunity to undergo

Table 1 Baseline characteristics by extent of ST segment depression

\begin{tabular}{|c|c|c|c|c|}
\hline \multirow[b]{2}{*}{ Characteristic } & \multicolumn{3}{|c|}{ ST segment depression } & \multirow[b]{2}{*}{ p Value } \\
\hline & None $(n=4160)$ & $1 \mathrm{~mm}(\mathrm{n}=3098)$ & $\geqslant 2 \mathrm{~mm}(\mathrm{n}=1590)$ & \\
\hline Age (years) & $63(53,71)$ & $66(57,73)$ & $68(60,75)$ & $<0.01$ \\
\hline Women & $33.5 \%$ & $37.3 \%$ & $31.6 \%$ & $<0.01$ \\
\hline Heart rate (beats/min) & $71(61,81)$ & $75(65,85)$ & $80(70,94)$ & $<0.01$ \\
\hline Systolic BP $(\mathrm{mm} \mathrm{Hg})$ & $135(120,150)$ & $140(122,155)$ & $140(120,155)$ & $<0.01$ \\
\hline Diastolic BP (mm Hg) & $80(70,89)$ & $80(70,90)$ & $80(70,90)$ & $<0.01$ \\
\hline Hypertension & $45.6 \%$ & $48.9 \%$ & $50.3 \%$ & $<0.01$ \\
\hline Diabetes & $17.3 \%$ & $19.2 \%$ & $19.8 \%$ & 0.03 \\
\hline Family history of CAD & $42.1 \%$ & $38.8 \%$ & $36.7 \%$ & $<0.01$ \\
\hline Hypercholesterolaemia & $41.7 \%$ & $43.0 \%$ & $41.9 \%$ & 0.51 \\
\hline Congestive heart failure & $5.0 \%$ & $7.4 \%$ & $8.4 \%$ & $<0.01$ \\
\hline Previous angina & $74.8 \%$ & $73.7 \%$ & $74.0 \%$ & 0.55 \\
\hline Previous MI & $31.1 \%$ & $29.3 \%$ & $34.8 \%$ & $<0.01$ \\
\hline Previous PTCA & $12.4 \%$ & $9.5 \%$ & $6.8 \%$ & $<0.01$ \\
\hline Previous CABG & $11.2 \%$ & $11.7 \%$ & $8.4 \%$ & $<0.01$ \\
\hline COPD & $2.8 \%$ & $2.6 \%$ & $3.6 \%$ & 0.12 \\
\hline PVD & $6.2 \%$ & $8.4 \%$ & $11.3 \%$ & $<0.01$ \\
\hline Enrolment Ml & $35.2 \%$ & $43.0 \%$ & $58.9 \%$ & $<0.01$ \\
\hline \multirow{5}{*}{$\begin{array}{l}\text { Regions } \\
\text { USA } \\
\text { Canada } \\
\text { Europe } \\
\text { Australia/NZ }\end{array}$} & & & & $<0.01$ \\
\hline & $58.8 \%$ & $26.6 \%$ & $14.6 \%$ & \\
\hline & $55.5 \%$ & $28.0 \%$ & $16.5 \%$ & \\
\hline & $40.6 \%$ & $38.7 \%$ & $20.7 \%$ & \\
\hline & $42.6 \%$ & $42.1 \%$ & $15.3 \%$ & \\
\hline
\end{tabular}



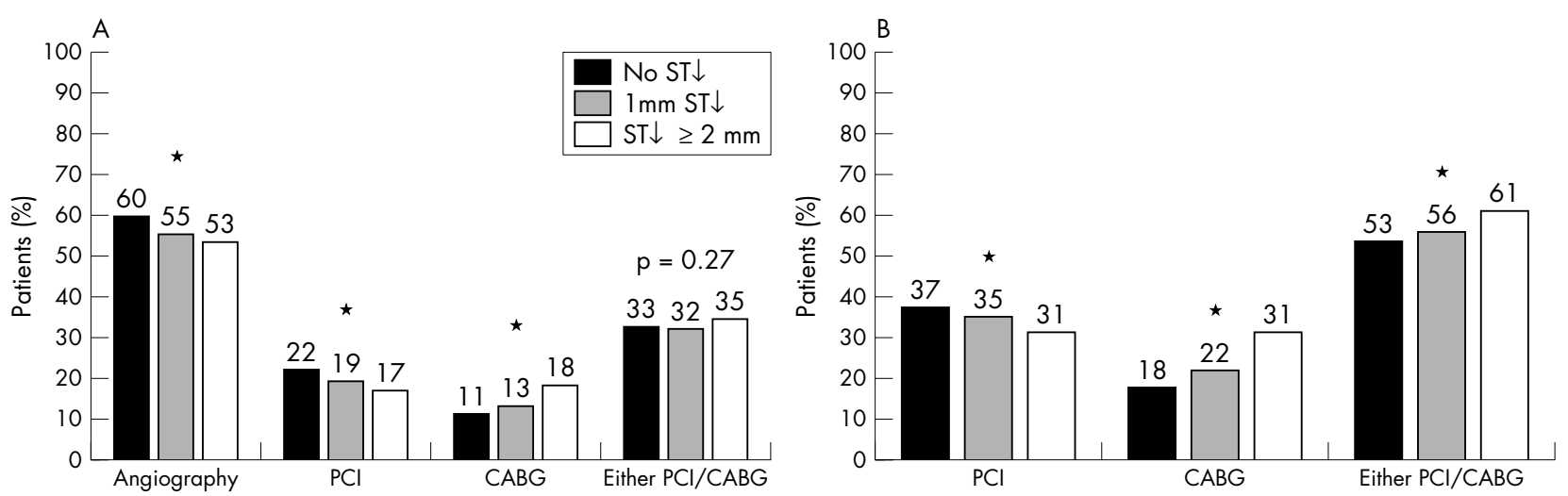

Figure 1 Use of angiography and revascularisation procedures across ST segment depression (ST $\downarrow$ ) categories (left) overall and (right) among patients who underwent angiography. CABG, coronary artery bypass graft surgery; $\mathrm{PCl}$, percutaneous coronary intervention. ${ }^{*} \chi{ }^{2}$ test for trend significant at $p<0.05$.

revascularisation) were included. The six day cut off was chosen because the median time to revascularisation in the cohort was six days (interquartile range 3-10 days). Survival curves were compared by the log rank test statistic. We used Cox regression analysis to examine the association between baseline variables and six month mortality. Given that revascularisation is not a baseline variable, it was included as a time dependent covariate, and the interaction between revascularisation status and the presence of ST segment depression $\geqslant 1 \mathrm{~mm}$ was examined. ${ }^{15}$

\section{RESULTS}

\section{Patient population}

Of the total 11453 study patients, ECG data were available for 10369 (91\%). Patients with missing ECG data were less likely to have a myocardial infarction on presentation and had lower frequency of prior revascularisation procedures. There were no other significant differences in baseline characteristics between the two groups. After exclusion of 1521 patients with ECG confounders, the final study sample comprised 8848 patients. The distribution of these patients across ST segment depression categories was as follows: 4160 (47\%) had no ST segment depression; 3098 (35\%) had ST segment depression of $1 \mathrm{~mm}$; and 1590 (18\%) had ST segment depression $\geqslant 2 \mathrm{~mm}$.

Table 1 provides baseline and clinical characteristics of study patients according to ST segment depression status. Patients with ST segment depression $\geqslant 2 \mathrm{~mm}$ were older,
Table 2 Variables associated with a higher mortality hazard at six months based on Cox regression analysis

\begin{tabular}{llll}
\hline Variable & HR & $95 \%$ Cl & $\chi^{2}$ \\
\hline Age & 1.06 & 1.05 to 1.07 & 128.6 \\
ST segment depression $\geqslant 1 \mathrm{~mm}$ & 1.96 & 1.59 to 2.41 & 39.1 \\
Diabetes & 1.74 & 1.43 to 2.12 & 31.0 \\
MI on enrolment & 1.57 & 1.31 to 1.89 & 23.4 \\
Congestive heart failure & 1.84 & 1.45 to 2.33 & 24.8 \\
COPD & 1.96 & 1.40 to 2.76 & 15.3 \\
PVD & 1.59 & 1.25 to 2.03 & 14.0 \\
Previous MI & 1.43 & 1.18 to 1.74 & 13.7 \\
Previous angina & 1.52 & 1.17 to 1.97 & 9.6 \\
Hypercholesterolaemia & 0.85 & 0.70 to 1.02 & 2.9 \\
\hline
\end{tabular}

$\mathrm{Cl}$, confidence interval; $\mathrm{HR}$, hazard ratio.

more likely to be men, and less likely to have undergone a previous PCI or CABG. The frequency of risk factors including hypertension and diabetes was higher in these patients and they more often had congestive heart failure, previous myocardial infarction, and peripheral vascular disease. In addition, the likelihood of presenting with myocardial infarction as the index event increased with the extent of ST segment depression (35\% among patients with no ST segment depression, $43 \%$ among patients with ST segment depression of $1 \mathrm{~mm}$, and 59\% among patients with ST segment depression $\geqslant 2 \mathrm{~mm} ; \mathrm{p}<0.01$ ). In keeping with the higher risk profile, six month mortality was significantly
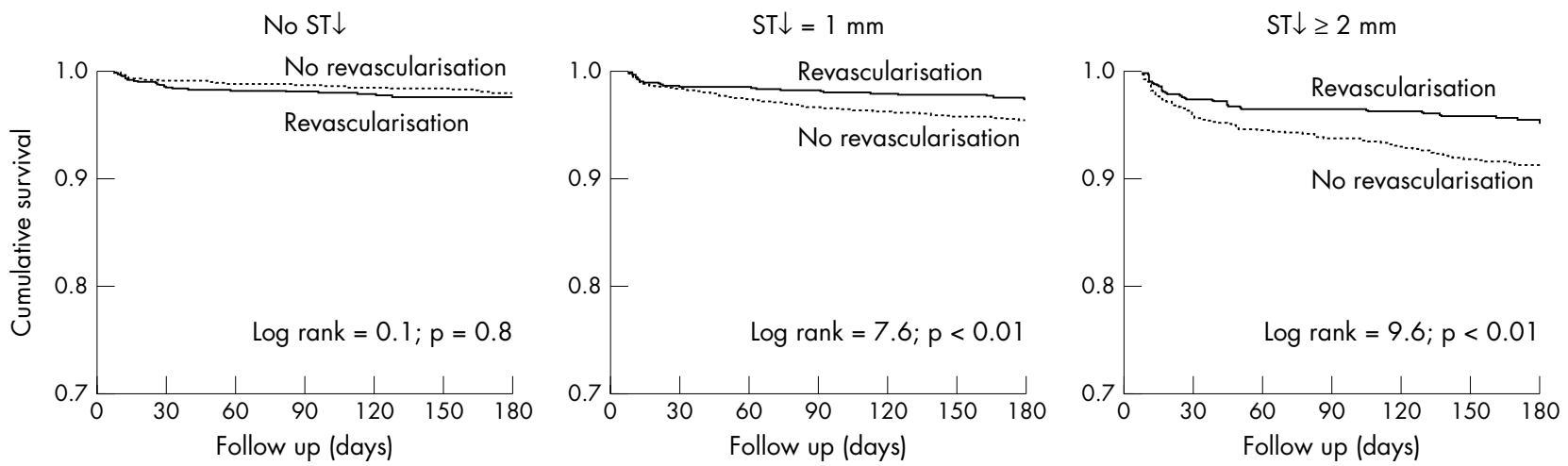

Figure 2 Unadjusted six month survival by ST segment category and revascularisation status. To reduce selection bias associated with treating patients who did not survive long enough to undergo revascularisation as non-revascularised patients, this analysis was restricted to patients who had survived to six days after admission. 

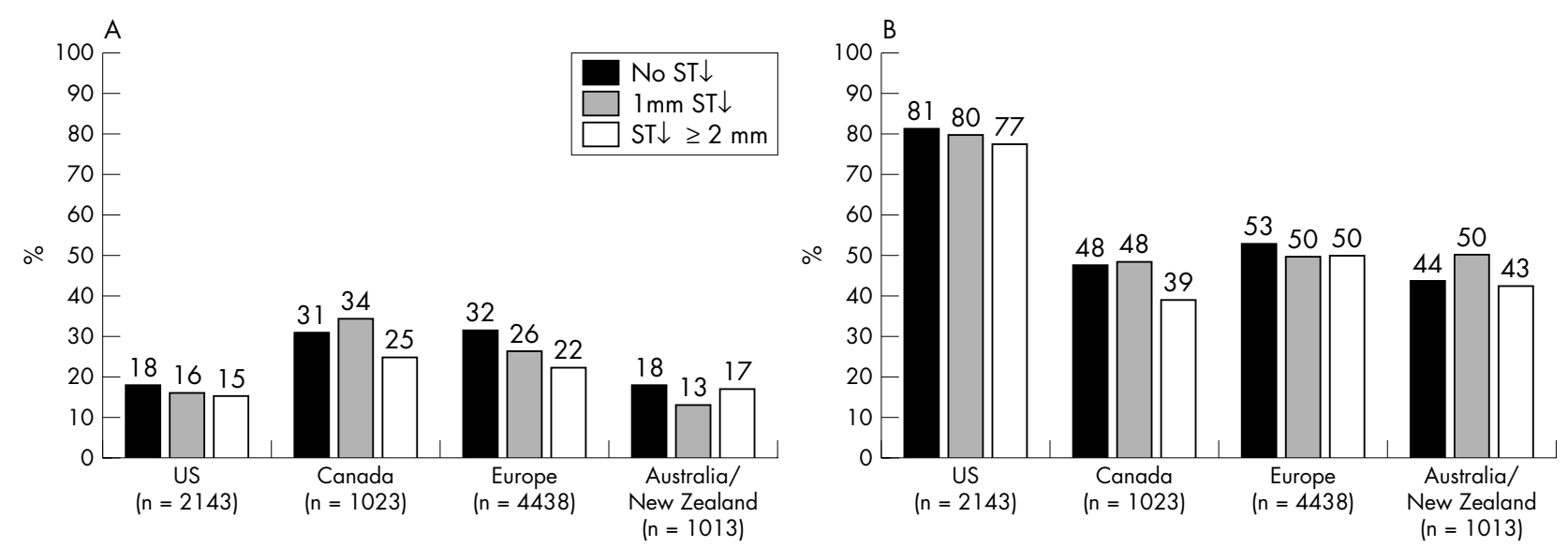

Figure 3 Use of diagnostic tests by ST segment depression category and geographic region: (A) stress tests; (B) angiography. ${ }^{*} \chi^{2}$ test for trend significant at $p<0.05$.

higher among patients with ST segment depression $\geqslant 2 \mathrm{~mm}$ (2.9\% among patients with no ST segment depression, $5.3 \%$ among patients with $1 \mathrm{~mm}$ ST segment depression, and $11.7 \%$ among patients with ST segment depression $\geqslant 2 \mathrm{~mm}$; $\mathrm{p}<0.01)$.

Figure 1 shows the rates of angiography, PCI, and CABG use across ST segment depression categories. There was an inverse relation between extent of ST segment depression and the use of angiography and PCI $(\mathrm{p}<0.01)$; however, patients with ST segment depression $\geqslant 2 \mathrm{~mm}$ were more likely to undergo CABG $(\mathrm{p}<0.01)$. Revascularisation patterns across ST segment depression categories were similar when the analysis was restricted to patients who had undergone angiography (fig l, right panel). Among patients with no ST segment depression, those who had a previous PCI or recurrent ischaemia were more likely to undergo coronary angiography, whereas women and older patients were less likely to do so. Similarly, among patients with ST segment depression $\geqslant 2 \mathrm{~mm}$, patients who were younger, were men, had hypercholesterolaemia, a family history of coronary artery disease, prior PCI, and no peripheral vascular disease, and did not have a myocardial infarction on enrolment, were more likely to undergo revascularisation. To ensure that our results were not influenced by the time window of the study - that is, the index hospitalisation-we examined 30 day rates of PCI and CABG by ST segment depression category. The patterns were similar to those observed during the index hospitalisation with cumulative 30 day PCI rates of $23.7 \%, 21 \%$, and $17.7 \%$ and cumulative CABG rates of $13.4 \%, 15.8 \%$, and $22.1 \%$ among patients with no ST segment depression, ST segment depression of $1 \mathrm{~mm}$, and ST segment depression $\geqslant 2 \mathrm{~mm}$, respectively.

Figure 2 shows the relation of revascularisation and six month mortality (among six day survivors) across the three ST segment depression categories. Revascularisation appeared to have no relation with survival among patients with no ST segment depression; however, it was associated with significantly better survival among patients with $1 \mathrm{~mm}$ ST segment depression (2.6\% among revascularised patients and $4.7 \%$ among non-revascularised patients, $\mathrm{p}<0.01)$ and among patients with ST segment depression $\geqslant 2 \mathrm{~mm}(4.8 \%$ among revascularised patients and $9.3 \%$ among non-revascularised patients, $\mathrm{p}<0.01$ ). In a multivariable Cox regression model, patient's age and ST segment depression $\geqslant 1 \mathrm{~mm}$ were the strongest predictors of six month mortality accounting for $55 \%$ of the model's predictive power (table 2 ). On inclusion of revascularisation status as a time dependent covariate, the main effect of revascularisation was non- significant. However, the interaction between revascularisation and the presence of ST segment depression $\geqslant 1 \mathrm{~mm}$ was significant (hazard ratio $0.62,95 \%$ CI 0.38 to 1.0 ) suggesting that revascularisation was beneficial for patients with ST segment depression of $\geqslant 1 \mathrm{~mm}$, after adjustment for baseline variables.

\section{International practice patterns}

Of the 8848 patients enrolled in the study, 2143 (24\%) were enrolled in the USA, $1023(12 \%)$ in Canada, 4438 (50\%) in Europe, 1013 (11\%) in Australia/New Zealand, and 231 (3\%) in other countries that were excluded from the analysis. Table 1 shows the distribution of ST segment depression across region of enrolment. Compared with the other regions, European countries enrolled a significantly higher number of patients with ST segment depression $\geqslant 2 \mathrm{~mm}$ (15\% in the USA, $17 \%$ in Canada, $21 \%$ in Europe, and $15 \%$ in Australia/ New Zealand, $\mathrm{p}<0.01$ ).

The use of stress tests was higher in Canada and Europe, whereas the rates of angiography use were significantly higher in the USA than in the other regions (fig 3). There were no significant differences in the use of angiography across ST segment depression categories. Figure 4 presents region specific procedure rates across ST segment depression categories. In general, use of PCI decreased with extent of ST segment depression category (fig 4, panel A). In contrast, rates of CABG increased with extent of ST segment depression (fig 4, panel B) in both the USA and Europe. The highest correlation between ST segment depression and CABG use was in the USA with rates of $17 \%$ in patients with no ST segment depression, $24 \%$ in patients with $1 \mathrm{~mm} \mathrm{ST}$ segment depression, and $33 \%$ in patients with ST segment depression $\geqslant 2 \mathrm{~mm}$ ( $\mathrm{p}$ value for trend $<0.01$ ). When we examined the combined revascularisation rates (for PCI or CABG), the only significant trends in procedure use across ST segment depression categories was observed in the USA ( fig 4, panel C). The patterns across ST segment depression categories remained consistent when revascularisation rates were calculated for only those patients who had undergone coronary angiography.

\section{DISCUSSION}

The key finding of our study was the paradoxical absence of a relation between the extent of baseline ST segment depression and the use of an invasive diagnostic and management strategy for patients with ACS. In fact, an invasive strategy was selected least often for those at highest risk for adverse outcomes. The potential consequences of this are twofold. 

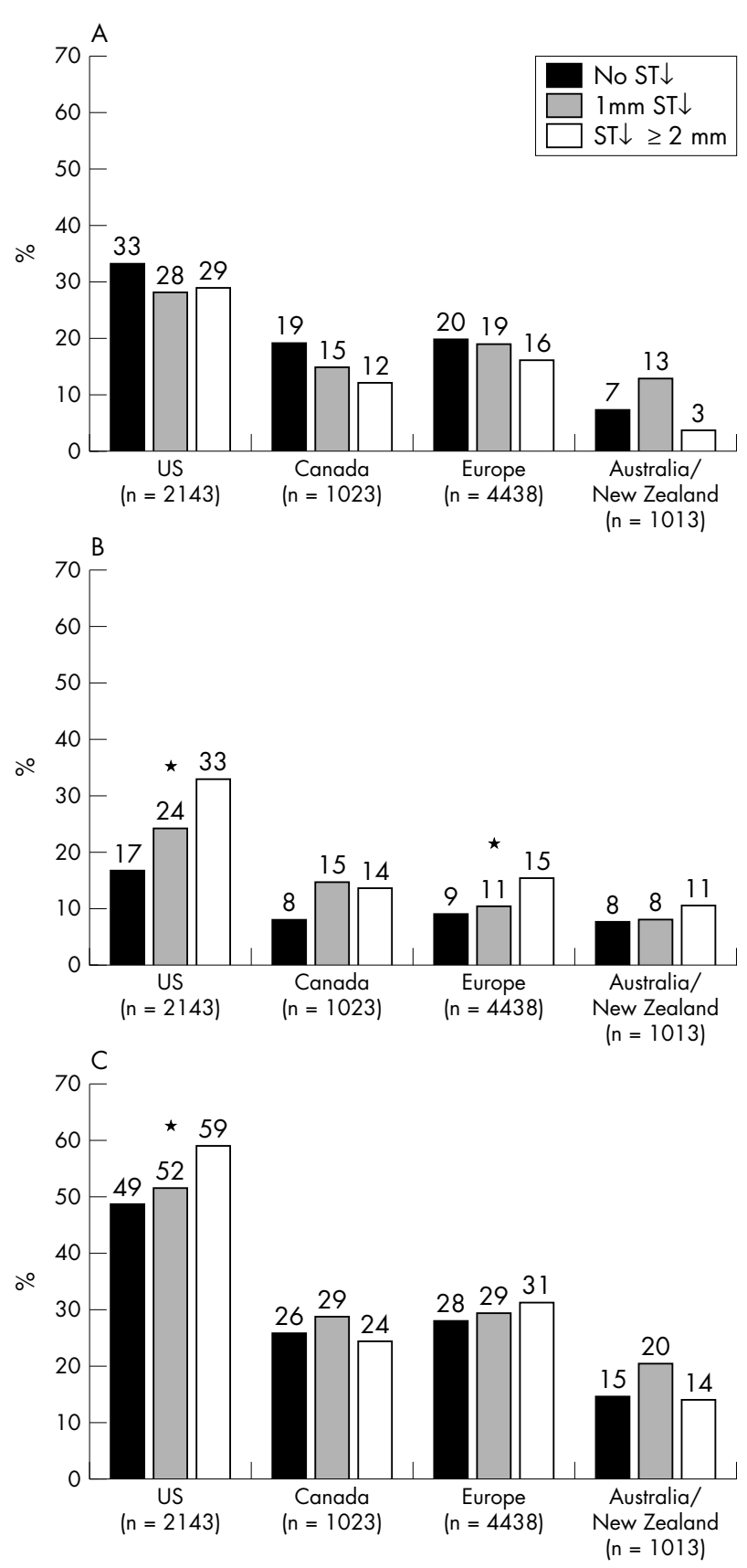

Figure 4 Use of revascularisation procedures by ST segment depression categories and geographic region: (A) PCl; (B) CABG; (C) either $\mathrm{PCl}$ or $\mathrm{CABG}$

Firstly, because our findings, like those of others, ${ }^{9} 1617$ suggest a greater benefit from revascularisation for patients with ST segment depression of $\geqslant 1 \mathrm{~mm}$, failure to apply the results of this simple risk stratification tool may result in suboptimal clinical outcomes in regions where angiography rates are low regardless of ECG presentation. Conversely, in regions where angiography rates are high regardless of ECG presentation, resource use and costs may not be optimised.

\section{Prior studies}

Our findings of the association between early revascularisation and mortality across ST segment depression categories, based on the largest database of patients with ACS with core laboratory ECG evaluations, are consistent with the results of subanalyses of the FRISC-II study. ${ }^{16}{ }^{17}$ In the FRISC-II ECG substudy, Diderholm et al ${ }^{16}$ found that among patients with ST segment depression (defined as $>0.5 \mathrm{~mm}$ ) an early invasive strategy was associated with a significant reduction in one year mortality (from $5.8 \%$ to $3.3 \%, p=0.004$ ). Holmvang et al ${ }^{17}$ extended this analysis to include cumulative ST segment depression and the number of leads with ST segment depression $>0.5 \mathrm{~mm}$. Similar to our findings, they found that invasive treatment was associated with lower mortality among all patients except those with minor ST segment deviations.

\section{International practice patterns}

Assessing performance and providing feedback have been described as integral components of improving quality of health care delivery. ${ }^{18}$ Our examination of international practice patterns between 1995 and 1998 is an excellent benchmark against which to measure the impact of recent American College of Cardiology/American Heart Association guidelines and European Society of Cardiology guidelines, which offer a class IA recommendation for the use of early invasive treatment for patients with ACS presenting with new or presumably new ST segment deviations. ${ }^{19}{ }^{20}$ Our study has several findings that are relevant to clinical practitioners as well as policymakers. Firstly, a higher percentage of patients with ST segment depression was enrolled in Europe $(59 \%)$ than in North America $(41 \%$ in the USA and $44 \%$ in Canada; table 1). This may contribute to the increased mortality documented in European countries in previous studies. ${ }^{21} 22$ Secondly, as documented previously, the USA had the highest rates of angiography among the regions (fig 3). ${ }^{23}$ A consequence of such an aggressive management strategy was the identification of the highest percentage of candidates for CABG not only among patients with ST segment depression $\geqslant 2 \mathrm{~mm}$ (33\% compared with $14 \%$ in Canada, $15 \%$ in Europe, and $11 \%$ in Australia/New Zealand) but also among patients with no ST segment depression (17\% compared with $8 \%$ in Canada, $9 \%$ in Europe, and $8 \%$ in Australia/New Zealand). This may, in part, explain the observed benefit from an early invasive risk stratification strategy compared with a conservative strategy in clinical trials. Thirdly, and most important, major opportunities remain to improve clinical decision making with respect to the use of revascularisation in all regions but especially in Canada and Europe. In these regions, there were no significant differences in revascularisation rates across ST segment depression categories, and only a third of the patients most likely to benefit from revascularisation received it. In the USA, although revascularisation rates appear more sensitive to the extent of ST segment depression, of the 59\% of patients without ST segment depression for whom revascularisation appears to offer no benefit, $81 \%$ underwent angiography and $49 \%$ underwent PCI or CABG. Channelling of these resources towards more high risk patients should result in more cost effective and efficient delivery of care.

Some limitations of our study should be noted. Owing to the observational nature of the study design and the fact that revascularisation was a post-randomisation event, the association between revascularisation and outcomes must be considered hypothesis generating. Secondly, our study examined practice patterns within the context of clinical trials, which may not be entirely representative of overall practice. However, to the extent that practice patterns among clinicians participating in clinical trials are likely to be more evidence based, even more opportunities to improve practice probably exist at a population level. Thirdly, protocols for GUSTO-IIB and PARAGON-A discouraged the use of early revascularisation unless necessitated by the presence of recurrent ischaemia. Although this may be a factor, it is 
unlikely to explain the large differences in practice patterns across ST segment categories in the four regions. This is substantiated by the similarity of patterns in PARAGON-B in which revascularisation decisions were left entirely to the practitioner's discretion. Fourthly, our study did not capture procedure rates beyond 30 days. To the extent that time to revascularisation, especially for CABG, is longer in Europe, our rates may underestimate the overall revascularisation rates in this region. Lastly, several countries were grouped together in the European region and the contributions of patients to the three trials differed significantly for many of the countries. The heterogeneity of countries within these regions is not accounted for in these analyses.

\section{Conclusions}

We found in data from three large international ACS trials with core laboratory ECG evaluations that revascularisation had no apparent impact on outcomes among patients with no ST segment depression but was associated with significantly lower mortality rates among patients with $\geqslant 1 \mathrm{~mm}$ ST segment depression. International practice patterns with respect to diagnostic and revascularisation procedures appear to be insensitive to the extent of ST segment depression on the baseline ECG. Major opportunities for more efficient delivery of care exist in all regions.

\section{ACKNOWLEDGEMENTS}

The GUSTO-IIB trial was supported in part by Guidant Corporation, Redwood City, California and by Ciba-Geigy, Summit, New Jersey. The PARAGON-A trial was supported by F Hoffman La-Roche Ltd, Basel, Switzerland. The PARAGON-B trial was supported by $\mathrm{F}$ Hoffmann-La Roche Ltd, Basel, Switzerland; Roche Diagnostics Corporation, Indianapolis, Indiana, USA; and Roche Diagnostics $\mathrm{GmbH}$, Mannheim, Germany

\section{Authors' affiliations \\ P Kaul ${ }^{*}$, Y Fu, P W Armstrong, University of Alberta, Edmonton, Alberta, Canada \\ L K Newby, D B Mark, G S Wagner, R A Harrington, C B Granger, \\ Duke University, Durham, North Carolina, USA \\ S G Goodman, Canadian Heart Research Centre and Terrence Donnelly Heart Centre, Division of Cardiology, St Michael's Hospital, University of Toronto, Toronto, Ontario, Canada \\ F Van de Werf, Gasthuisberg University Hospital, Leuven, Belgium E M Ohman, University of North Carolina Medical Center, Chapel Hill, North Carolina, USA}

*Also Duke University, Durham, North Carolina, USA

\section{APPENDIX}

\section{List of countries (number of patients enrolled in all three trials)}

USA (2143); Canada (1023); Europe (4438): Belgium (665); France (585); Germany (176); Italy (1003); Netherlands (755); Spain (670); Sweden (188); United Kingdom (179); Switzerland (68); Poland (451); Portugal (28); Iceland (67); Finland (182); Denmark (54); Hungary (145); Australia/ New Zealand (1013): Australia (855); New Zealand (158); Other (231): Argentina (159); Brazil (4); Israel (76); South Africa (46).

\section{REFERENCES}

1 Wallentin L. Non-ST-elevation acute coronary syndrome: fuel for the invasive strategy. Lancet 2002;360:738-9.

2 Kaul P, Newby KL, Fu Y, for the PARAGON-B Investigators, et al. Troponin T and quantitative ST-segment depression offer complementary prognostic information in the risk stratification of acute coronary syndrome patients. J Am Coll Cardiol 2003;41:371-80.

3 Kaul P, Fu Y, Chang W-C, for the PARAGON-A and GUSTO-IIB Investigators, et al. Prognostic value of ST-segment depression in acute coronary syndromes: insights from PARAGON-A applied to GUSTO-IIB. J Am Coll Cardiol 2001;38:64-71.

4 Holmvang L, Clemmensen P, Wagner G, et al. Admission standard electrocardiogram for early risk stratification in patients with unstable coronary artery disease not eligible for acute revascularization therapy: a thrombin inhibition in myocardial infarction (TRIM) substudy. Am Heart $J$ 1999; 137:24-33

5 Hyde TA, French JK, Wong CK, et al. Four year survival of patients with acute coronary syndromes without ST-segment elevation and prognostic significance of $0.5 \mathrm{~mm}$ ST-segment depression. Am J Cardiol 1999;84:379-85.

6 Holmvang L, Luscher MS, Clemmensen P, et al. Very early risk stratification using combined ECG and biochemical assessment in patients with unstable coronary artery disease: a thrombin inhibition in myocardial infarction (TRIM) substudy. Circulation 1998;98:2004-9.

7 FRISC II Investigators. Invasive compared with non-invasive treatment in unstable coronary artery disease: FRISC II prospective randomized multicenter study. FRISC II investigators. Lancet 1999;354:708-15.

8 Cannon CP, Weintraub WS, Demopoulos L, et al. Comparison of early invasive and conservative strategies in patients with unstable coronary syndromes treated with glycoprotein Ilb/Illa inhibitor tirofiban. N Engl J Med 2001;344:1879-87.

9 Solomon DH, Stone PH, Glynn RJ, et al. Use of risk stratification to identify patients with unstable angina least likeliest to benefit from an invasive versus conservative management strategy. J Am Coll Cardiol 2001;38:969-76.

10 GUSTO-IIB Investigators. The global use of strategies to open occluded coronary arteries: a comparison of recombinant hirudin with heparin for the treatment of acute coronary syndromes. GUSTO-IIB investigators. NEngl J Med 1996;335:775-82.

11 PARAGON Investigators. International, randomized, controlled trial of lamifiban (a platelet glycoprotein Ilb/Illa) inhibitor), heparin, or both in unstable angina. The PARAGON investigators. Circulation 1998;97:2386-95

12 PARAGON-B Investigators. Randomized, placebo-controlled trial of titrated intravenous lamifiban for acute coronary syndromes. The PARAGON-B investigators. Circulation 2002;105:316-21.

13 Newby LK, Ohman EM, Christenson RH, et al. Benefit of glycoprotein Ilb/Illa inhibition in patients with acute coronary syndromes and troponin t-positive status: The PARAGON-B Troponin T substudy. Circulation 2001;103:2891-6.

14 Anderson JR, Cain KC, Gelber RD. Analysis of survival by tumor response. J Clin Oncol 1983;1:710-9.

15 Kalbfleisch JD, Prentice RL. The statistical analysis of failure time data. New York: John Wiley \& Sons, 1980:122-7.

16 Diderholm E, Andren B, Frostfeldt G, et al. ST depression in ECG at entry indicates severe coronary lesions and large benefits of an early invasive treatment strategy in unstable coronary artery disease: the FRISC II ECG substudy. Eur Heart J 2002;23:41-9.

17 Holmvang L, Clemmensen P, Lindahl B, et al. Quantitative analysis of the admission electrocardiogram identifies patients with unstable coronary artery disease who benefit the most from early invasive treatment. J Am Coll Cardiol 2003:41:905-15.

18 Califf RM, Peterson ED, Gibbons RJ, et al. Integrating quality into the cycle of therapeutic development. J Am Coll Cardiol 2002;40:1895-901.

19 Braunwald E, Antman EM, Beasley JW, et al. ACC/AHA guidelines for the management of patients with unstable angina and non-ST-segment elevation myocardial infarction: a report of the American College of Cardiology/ American Heart Association Task force on practice guidelines (committee on the management of patients with unstable angina). J Am Coll Cardiol 2000;36:970-1062.

20 Bertrand ME, Simoons ML, Fox KAA, et al. Management of acute coronary syndromes in patients presenting without persistent ST-segment elevation. Task force of the European Society of Cardiology. Eur Heart J 2002;23:1809-40.

21 Akkerhuis KM, Deckers JW, Boersma E, et al. Geographic variability in outcomes within an international trail of glycoprotein $\mathrm{Ilb} / \mathrm{Illa}$ inhibition in patients with acute coronary syndromes: results from PURSUIT. Eur Heart $J$ 2000;21:371-81

22 Fox KAA, Goodman S, Bigonzi F, et al. Inter-regional differences and outcome in unstable angina: analysis of the international ESSENCE trial. Eur Heart J 2000;21:1433-9.

23 Yusuf S, Flather M, Pogue J, et al. Variations between countries in invasive cardiac procedures and outcomes in patients with suspected unstable angina or myocardial infarction without initial ST elevation. Lancet 1998;352:507-14 